\title{
Diethylstilbestrol Syndrome
}

National Cancer Institute

\section{Source}

National Cancer Institute. Diethylstilbestrol Syndrome. NCI Thesaurus. Code C113422.

A disorder likely to occur in children and grandchildren of a woman treated with diethylstilbestrol during pregnancy. Manifestations include vaginal adenosis, cervical malformations, vaginal septae, genital tract anomalies or Fallopian tube anomalies causing subsequent fertility problems. 